\title{
Unfilled Prescriptions of Medicare Beneficiaries: Prevalence, Reasons, and Types of Medicines Prescribed
}

\author{
Jae Kennedy, PhD; Iulia Tuleu, MD, MHPA; and Katherine Mackay, MHPA
}

\begin{abstract}
BACKGROUND: Despite the proven efficacy of prescription regimens in reducing disease symptoms and preventing or minimizing complications, poor medication adherence remains a significant public health problem. Medicare beneficiaries have high rates of chronic illness and prescription medication use, making this population particularly vulnerable to nonadherence. Failure to fill prescribed medication is a key component of nonadherence.

OBJECTIVES: To (1) determine the rates of self-reported failure to fill at least 1 prescription among a sample of Medicare beneficiaries in 2004, (2) identify the reasons for not filling prescribed medication, (3) examine the characteristics of Medicare beneficiaries who failed to fill their prescription(s), and (4) identify the types of medications that were not obtained.
\end{abstract}

METHODS: The study is a secondary analysis of the 2004 Medicare Current Beneficiary Survey (MCBS), an ongoing national panel survey conducted by the Centers for Medicare \& Medicaid Services (CMS). Medicare beneficiaries living in the community $(\mathrm{N}=14,464)$ were asked: "During the current year [2004], were there any medicines prescribed for you that you did not get (please include refills of earlier prescriptions as well as prescriptions that were written or phoned in by a doctor)?" Those who responded "yes" to this question ( $n=664)$ were asked to identify the specific medication(s) not obtained. Rates of failure to fill were compared by demographic and income categories and for respondents with versus without self-reported chronic conditions, identified by asking respondents if they had ever been told by a doctor that they had the condition. Weighted population estimates for nonadherence were calculated using Professional Software for SUrvey DAta ANalysis for Multi-stage Sample Designs (SUDAAN) to account for the MCBS multistage stratified cluster sampling process. Unweighted counts of the prescriptions not filled by therapeutic class were calculated using Statistical Analysis Software (SAS).

RESULTS: In 2004, an estimated 1.6 million Medicare beneficiaries (4.4\%) failed to fill or refill 1 or more prescriptions. The most common reasons cited for failure to fill were: "thought it would cost too much" (55.5\%), followed by "medicine not covered by insurance" $(20.2 \%)$, "didn't think medicine was necessary for the condition" $(18.0 \%)$, and "was afraid of medicine reactions/contraindications" $(11.8 \%)$. Rates of failure to fill were significantly higher among Medicare beneficiaries aged 18 to 64 years eligible through Social Security Disability Insurance (10.4\%) than among beneficiaries aged 65 years or older $(3.3 \%, P<0.001)$. Rates were slightly higher for women than for men (5.0 vs. $3.6 \%, P=0.001)$, for nonwhite than for white respondents ( $5.5 \%$ vs. $4.2 \%, P=0.010)$, and for dually eligible Medicaid beneficiaries than for those who did not have Medicaid coverage ( $6.3 \%$ vs. $4.0 \% P=0.001)$. Failure-to-fill rates were significantly higher among beneficiaries with psychiatric conditions $(8.0 \%, P<0.001)$; arthritis (5.2\%, $P<0.001)$; cardiovascular disease $(5.2 \%, P=0.003)$; and emphysema, asthma, or chronic obstructive pulmonary disease $(6.6 \%, P<0.001)$ than among respondents who did not report those conditions, and the rate for respondents who reported no chronic conditions was $2.5 \%$. Rates were higher for those with more self-reported chronic conditions $(3.2 \%, 4.0 \%$, $4.3 \%$, and $5.9 \%$ for those with $1,2,3$, and 4 or more conditions, respectively, $P<0.001$ ). Among the prescriptions not filled (993 prescriptions indentified by 664 respondents), central nervous system agents, including nonsteroidal anti-inflammatory drugs, were most frequently identified $(23.6 \%, n=234)$, followed by cardiovascular agents $(18.3 \%, n=182)$ and endocrine/metabolic agents $(6.5 \%, \mathrm{n}=65)$. Of the reported unfilled prescriptions, $8.1 \%$ were for antihyperlipidemic agents, $5.4 \%$ were for antidepressant drugs, $4.6 \%$ were for antibiotics, and $29.9 \%$ were for unidentified therapy classes.

CONCLUSION: Most Medicare beneficiaries fill their prescriptions, but some subpopulations are at significantly higher risk for nonadherence associated with unfilled prescriptions, including working-age beneficiaries, dual-eligible beneficiaries, and beneficiaries with multiple chronic conditions. Self-reported unfilled prescriptions included critical medications for treatment of acute and chronic disease, including antihyperlipidemic agents, antidepressants, and antibiotics.

J Manag Care Pharm. 2008;14(6):553-60

Copyright $\odot$ 2008, Academy of Managed Care Pharmacy. All rights reserved.

\section{What is already known about this subject}

- Prescription medication nonadherence is a serious concern in the Medicare population because of high rates of chronic illness and heavy medication usage.

- Drug costs and inadequate insurance coverage are the most common reasons offered by Medicare patients for failing to fill a prescription

- The new 2006 Medicare Part D prescription drug benefit is intended to reduce the rate of cost-related nonadherence.

\section{What this study adds}

- Prior to the implementation of the Medicare Part D prescription drug benefit, the estimated rate of failure to fill at least 1 prescription among all Medicare beneficiaries was $4.4 \%$. A belief that the medication would "cost too much" was cited as a reason for failure to fill by $55.5 \%$ of those failing to fill at least 1 prescription, or $2.4 \%$ of respondents overall.

- Rates of failure to fill were higher among working-age disabled beneficiaries than among those aged 65 years or older $(10.4 \%$ vs. $3.3 \%$, respectively), and among dually eligible (Medicare/ Medicaid) beneficiaries (6.3\%) than among those without Medicaid coverage (4.0\%).

- Rates of failure to fill were higher for beneficiaries with selfreported psychiatric conditions (8.0\%) and beneficiaries with 4 or more self-reported chronic conditions (5.9\%); the rate was $2.5 \%$ for respondents reporting no chronic conditions.

- Of prescriptions not filled, 24\% were for central nervous system agents, including nonsteroidal anti-inflammatory drugs; $18 \%$ were for cardiovascular agents; $7 \%$ were for endocrine/metabolic agents; and 30\% were for unidentified therapy classes. 
$\mathrm{P}$ rescription drugs are essential to the prevention and treatment of disease, and adherence to drug regimens is a primary determinant of successful clinical outcomes. ${ }^{1}$ Unfortunately, drugs are not always taken as prescribed. ${ }^{2}$ Despite the proven efficacy of prescription regimens in reducing disease symptoms and preventing or minimizing complications, poor medication adherence remains a significant public health problem. ${ }^{3}$ Nonadherence is of particular concern in the Medicare population because of beneficiaries' relatively high rates of chronic illness ${ }^{4}$ and heavy medication usage. ${ }^{5}$ Potential health risks of nonadherence are particularly high for people with severe or chronic conditions. For example, patients aged 65 years and older with chronic heart failure are prescribed an average of 7.5 prescriptions daily at hospital discharge, ${ }^{6}$ and nonadherence to this medical regimen is among the leading causes of hospitalization for heart failure. ${ }^{7}$ Likewise, Medicare and Medicaid patients with chronic psychiatric conditions who fail to take their medications are at higher risk of hospitalization and institutionalization. ${ }^{8}$

The objectives of this study are to (1) determine the rates of self-reported failure to fill at least 1 prescription among a sample of Medicare beneficiaries in 2004, (2) identify the reasons for not filling prescribed medication, (3) examine the characteristics of Medicare beneficiaries who failed to fill their prescription(s), and (4) identify the types of medications that were not obtained. These population estimates will help to identify the scope of the nonadherence problem in the Medicare program and will establish a baseline for assessing the impact of the 2006 Medicare prescription drug program.

Recent health policy research in this area has focused mainly on cost-related nonadherence (not filling or taking a medication as prescribed because of drug cost). National health surveys indicate that a growing number of adults in the United States cannot afford to fill their prescriptions. ${ }^{9}$ Specific rates vary by survey sample frame and question design, ranging from $1.6 \%$ to $22 \%{ }^{10}$ Most U.S. studies focus exclusively on seniors, ${ }^{11-17}$ but several allage surveys suggest that cost-related nonadherence is most common among younger (aged 18-64 years) adults. ${ }^{18-20}$ Other patient attributes positively associated with cost-related nonadherence are racial or ethnic minority status, ${ }^{12,17}$ female gender, ${ }^{18}$ lack of health insurance or prescription drug coverage, $, 16,17,21,22$ low income, ${ }^{18}$ and disability or chronic illness. ${ }^{18,23}$

Yet, clinicians observe that patients with similar health conditions, sociodemographic attributes, and socioeconomic status may make very different choices when it comes to filling their prescriptions. ${ }^{24}$ These differences in adherence are often attributed to the quality of the patient-provider interactions; ${ }^{25-27}$ the salient nontherapeutic features of the drugs prescribed, including the complexity of regimens; ${ }^{28,29}$ and the occurrence of unpleasant sideeffects or drug interactions. ${ }^{30-33}$ In short, filling a prescription and taking the medication as prescribed is a complex health behavior determined by the patient's perceptions of drug costs and benefits and mediated by various provider and health system attributes. ${ }^{34}$
Much of the literature on medication adherence assumes a rational decision-making process where patients weigh the perceived therapeutic benefits of each medication against the cost of filling the prescription and restrict use of high-cost, lowbenefit medications. ${ }^{35,36}$ General evidence of price sensitivity can be found in some studies of insurance claims data that associate lower levels of drug utilization with higher levels of cost-sharing, ${ }^{37}$ but the research findings are inconsistent. ${ }^{38}$ Among commercially insured adults, the introduction of prescription coverage tiers, with different copayments for different tiers, appears to reduce program costs, in part by substitution of relatively low-cost but therapeutically equivalent medications, but does not adversely affect patient treatment regimens or health status. ${ }^{38-40}$ However, it appears that more vulnerable populations, including patients with chronic conditions and low incomes, are more sensitive to cost-sharing increases or coverage limits. ${ }^{38,41,42}$

Although a number of studies have used Medicare program data to assess rates of prescription drug nonadherence among enrollees with chronic health conditions, ${ }^{4,13,14,20-23}$ there have been no detailed analyses of which prescriptions were not filled. ${ }^{43,44}$ This paper fills these research gaps and establishes baseline data prior to implementation of the new Medicare drug benefit.

\section{Methods}

\section{Data Source}

The Medicare Current Beneficiary Survey (MCBS) is a nationally representative panel survey administered by the Centers for Medicare \& Medicaid Services (CMS). The MCBS employs a stratified multistage sampling strategy and includes sample weights derived from the U.S. Decennial Census to make inferences about the total program population. The sample is drawn from 107 primary sampling units (PSUs) and 1,237 ZIP codes within these PSUs. Target numbers are developed for specific age groups, with oversampling of younger beneficiaries (aged 18-44 years and 45-64 years) and older beneficiaries (aged 85 years or older). ${ }^{45}$

This study analyzes responses to the 2004 MCBS Access to Care Survey, purchased from the Research Data Assistance Center (ResDAC), a CMS contractor that provides technical assistance to researchers who use Medicare and/or Medicaid data. The Access to Care sample consists of a random cross-section of all beneficiaries enrolled in the Medicare program as of January 1 , 2004, who were alive and enrolled at the time of the 2004 fall interview round (September-December). While the Access to Care sample included both community- and facility-dwelling beneficiaries, the prescription drug access questions used in this analysis were asked only of the 14,464 community-dwelling elderly and nonelderly enrollees.

\section{Nonadherence Rates and Causes}

In the 2004 MCBS Access to Care Survey, 664 respondents (4.6\%) answered "yes," and 13,800 (95.4\%) answered "no" or 
"don't know" to the following question: "During the current year, were there any medicines prescribed for you that you did not get (please include refills of earlier prescriptions as well as prescriptions that were written or phoned in by a doctor)?" Respondents who said they had not filled a prescription were asked to select 1 or more reasons why the prescription was not filled.

Rates of failure to fill were calculated for the entire Medicare population and for beneficiaries in specific risk groups. Rates were calculated for 9 categories of self-reported chronic diseases: arthritis, hypertension, cardiovascular disease, psychiatric conditions, cancer, diabetes, respiratory disease, stroke or brain hemorrhage, and neurological disease. Self-reported conditions were identified by asking respondents "Has a doctor ever told you that you had ...?" and then naming the condition. A count of comorbidities was then derived and converted into a categorical variable. Rates of self-reported failure to fill medications for those with the chronic condition(s) were compared with those without the condition(s), using the Professional Software for SUrvey DAta ANalysis for Multi-stage Sample Designs (SUDAAN) CHISQ test, analogous to the Pearson chi-square test for simple random samples. ${ }^{46}$

\section{Unfilled Prescriptions}

Nonadherent respondents were asked to identify the drugs they were prescribed but did not obtain, and the interviewer typed their responses into 1 or more text fields. Among the 664 respondents who reported that they did not get a medication prescribed to them in 2004, a total of 993 drugs were identified, but a large portion of these responses (29.9\%) were not interpretable (such responses are either lacking an identifiable drug name or merely indicate a vague category of medication [e.g., "some allergy medication"]; these responses were eliminated from the analysis because the drug name or therapy class could not be identified with absolute certainty). Because the unit of analysis is the script, not the patient, only unweighted counts are provided.

A 2-level classification system was developed for this study using Drug Facts and Comparisons (2007), a reference book for pharmacists and health care professionals. ${ }^{47}$ The therapeutic scheme provides 2 levels of organization: (a) by body system such as cardiovascular or central nervous system and (b) by therapeutic indication such as antidepressant or narcotic analgesic. Eight primary classes and 36 subclasses were developed. The class "miscellaneous" consisted of all classes with a prevalence of use $\leq 1 \%$. Similarly, the subclass "other" within each class represented a sum of all subclasses with a prevalence of use $\leq 1 \%$.

\section{Results}

An estimated 1.6 million Medicare beneficiaries (4.4\%) failed to fill or refill 1 or more prescriptions in 2004 (Table 1). The most common reasons cited for failure to fill were: "thought it would cost too much" ( $55.5 \%$, estimated $n=898,910)$, followed by "medicine not covered by insurance" (20.2\%, estimated $\mathrm{n}=326,970$ ). Noneconomic reasons for failing to fill a prescription, including "didn't think medicine was necessary for the condition" $(18.0 \%$, estimated $n=291,990)$ and "was afraid of medicine reactions/contraindications" (11.8\%, estimated $n=190,540)$, were less frequently cited by Medicare beneficiaries.

Table 2 shows estimated rates of failure to fill by subpopulation. Rates were significantly higher among Medicare beneficiaries aged 18 to 64 years, eligible through Social Security Disability Insurance, than among those aged 65 years or older $(10.4 \%$ vs. $3.3 \%$, respectively; chi-square $=97.8 ; P<0.001$ ). Rates were slightly higher for women than for men $(5.0 \%$ vs. $3.6 \%$, respectively; chisquare $=12.0 ; P=0.001$ ), for nonwhite than for white respondents (5.5\% vs. $4.2 \%$, chi-square $=6.8, P=0.010)$, and for dually eligible Medicaid beneficiaries than for those not covered by Medicaid (6.3\% vs. $4.0 \%$, chi-square $=15.1, P=0.001)$. Beneficiaries with annual incomes $>\$ 30,000$ were less likely to report failure to fill than were beneficiaries with incomes $\leq \$ 30,000$ (3.2\% for incomes $>\$ 30,000,4.9 \%-5.0 \%$ for lower-income groups, chi-square $=11.5$, $P<0.001)$. Failure-to-fill rates were significantly higher among beneficiaries with psychiatric conditions $(8.0 \%$, chi-square $=37.4$, $P<0.001$ ), arthritis (5.2\%, chi-square $=26.3, P<0.001$ ), cardiovascular disease $(5.2 \%$, chi-square $=9.0, P=0.003)$, and emphysema, asthma, or chronic obstructive pulmonary disease $(6.6 \%$, chisquare $=20.0, P<0.001)$. The likelihood of not filling a prescription increased with the number of comorbid conditions (rates of $3.2 \%, 4.0 \%, 4.3 \%$, and $5.9 \%$ for respondents reporting $1,2,3$, and 4 or more conditions, respectively; chi-square $=7.3 ; P<0.001$ ), and among those reporting no chronic conditions, the rate of failure to fill was $2.5 \%$.

Table 3 lists unweighted counts of prescriptions not filled. In contrast to the previous tables, the unit of analysis is the prescription, not the respondent, and each respondent who reported failure to fill could list up to 3 prescriptions. Responses were entered verbatim by interviewers, leading to a large portion of ambiguous descriptions-approximately $30 \%$ of all responses were classified as "untranslatable" and excluded from the analysis. Such responses either lacked an identifiable drug name or listed a vague category of medication (e.g., "some allergy medication").

Among the prescriptions not filled, central nervous system agents, including nonsteroidal anti-inflammatory drugs (NSAIDs), were most frequently identified $(23.6 \%, n=234)$, followed by cardiovascular agents $(18.3 \%, \mathrm{n}=182)$, and endocrine/metabolic agents $(6.5 \%, \mathrm{n}=65)$. If ranked by subclass, antihyperlipidemic agents $(8.1 \%, \mathrm{n}=80)$, NSAIDs $(6.9 \%, \mathrm{n}=69)$, antidepressants $(5.4 \%, n=54)$, and antibiotics $(4.6 \%, n=46)$ were most prevalent among the prescriptions that Medicare beneficiaries fail to fill.

\section{Discussion}

This study extends prior research on drug-use patterns observed among Medicare beneficiaries. As opposed to characterizing the number and type of prescriptions filled by Medicare beneficiaries, ${ }^{4}$ this study provides a detailed analysis of the number and types 


\section{TABLE 1 Rate and Reasons for Medicare Beneficiaries Not Filling or Refilling Prescriptions}

\begin{tabular}{|c|c|c|}
\hline $\begin{array}{l}\text { One or More Unfilled Prescriptions } \\
\text { (Number of Respondents) }\end{array}$ & $\begin{array}{l}\text { Estimated } \\
\text { Population }\end{array}$ & $\begin{array}{c}\% \text { of } \\
\text { Population }\end{array}$ \\
\hline \multicolumn{3}{|l|}{$\begin{array}{l}\text { During 2004, were any medicines prescribed } \\
\text { for you that you did not get (please include } \\
\text { refills of earlier prescriptions as well as } \\
\text { prescriptions that were written or phoned in } \\
\text { by a doctor)? }\end{array}$} \\
\hline No & $35,294,380$ & 95.6 \\
\hline Yes $(n=664)$ & $1,620,200$ & 4.4 \\
\hline \multicolumn{3}{|l|}{ If yes, why? } \\
\hline Thought it would cost too much $(n=371)$ & 898,910 & 55.5 \\
\hline Medicine not covered by insurance $(n=145)$ & 326,970 & 20.2 \\
\hline $\begin{array}{l}\text { Didn't think medicine was necessary for the } \\
\text { condition }(n=117)\end{array}$ & 291,990 & 18.0 \\
\hline $\begin{array}{l}\text { Was afraid of medicine reactions/ } \\
\text { contraindications }(n=74)\end{array}$ & 190,540 & 11.8 \\
\hline Don't like to take medicine $(n=45)$ & 109,580 & 6.8 \\
\hline Felt better, didn't need medicine $(\mathrm{n}=32)$ & 80,790 & 5.0 \\
\hline $\begin{array}{l}\text { Didn't think medicine would help condition } \\
(\mathrm{n}=32)\end{array}$ & 74,690 & 4.6 \\
\hline Didn't have a way to get medicine $(n=24)$ & 52,250 & 3.2 \\
\hline Didn't have time $(\mathrm{n}=11)$ & $28,620^{a}$ & 1.8 \\
\hline Couldn't get the medicine soon enough $(n=8)$ & $20,690^{a}$ & 1.3 \\
\hline No pharmacy convenient $(n=4)$ & $8,730^{\mathrm{a}}$ & 0.5 \\
\hline Other $(n=41)$ & 92,560 & 5.7 \\
\hline
\end{tabular}

Source: 2004 Medicare Current Beneficiary Survey, Access to Care File, community resident sample

astimate unstable; relative standard error (standard errorlestimate) $>30 \%$.

of prescriptions not filled and the reasons why beneficiaries chose not to fill these prescriptions. Therefore, this analysis details one specific type of prescription nonadherence: the decision to not fill a prescription. Overall, a relatively small proportion of program participants (4.4\%) fail to fill or refill their prescriptions, confirming a previous analysis by Craig et al., whose analysis of MCBS data using a method similar to ours found that the percentages of seniors reporting a failure to fill at least 1 prescription were $2.4 \%$ in $1996,2.1 \%$ in $1997,2.3 \%$ in 1998 , and $2.8 \%$ in $1999 .{ }^{14}$ Unfortunately, even a small proportion of a very large program results in a large number-an estimated 1.6 million Medicare beneficiaries - at risk of adverse health consequences resulting from failure to fill or refill a prescription.

The likelihood of not filling a prescription is significantly higher for some subgroups, including women, nonwhite beneficiaries, beneficiaries with annual household incomes of $\leq \$ 30,000$, and dually eligible (Medicare + Medicaid) beneficiaries. Targeted health education efforts and/or insurance subsidies may reduce these disparities and improve adherence.
This study also finds that failing to fill a prescription is more common among beneficiaries with specific chronic conditions like psychiatric, respiratory, and cardiovascular disorders. Moreover, the more chronic conditions a respondent identifies, the more likely he or she is not to fill at least 1 prescription. This finding is broadly consistent with other Medicare studies, which find higher rates of nonadherence among adults with poor health, chronic disease, and disabilities. ${ }^{18,20,23}$ These disparities may be explained by another factor not included in this analysisthe number of drugs prescribed. Simply put, a higher number of prescriptions presents more frequent opportunities for nonadherence, and patients with more serious chronic conditions or multiple chronic conditions are prescribed more medicines than are those without chronic conditions. We found that the rate of failure to fill was higher for disabled beneficiaries aged 18 to 64 years (10.4\%) than for beneficiaries aged 65 years or older (3.3\%). Similarly, Soumerai et al.'s analysis of a national sample of noninstitutionalized Medicare enrollees, conducted 1 year prior to the implementation of Medicare Part D, found a higher overall rate of cost-related nonadherence among disabled (29.4\%) than among elderly (12.6\%) Medicare beneficiaries. ${ }^{20}$

From a clinical perspective, some forms of nonadherence are clearly more troublesome than others. For example, one of the most common subclasses of unfilled prescriptions was NSAIDs ( $n=69)$, drugs that have clinically similar and relatively inexpensive over-the-counter (OTC) substitutes. Failing to fill 1 of these prescriptions is unlikely to result in adverse health outcomes. In contrast, other subclasses of central nervous system agents are critical in the management of serious chronic disease (antidepressants, anticonvulsants, antipsychotics, etc.) and do not have OTC substitutes. Similar clinical concerns may arise with other classes or subclasses of prescriptions, including cardiovascular agents and antibiotics, and failure to take these medications as prescribed has the potential to lead to declining health status, hospitalization, and premature death. .-8 $^{\text {- }}$

Finally, drug costs and lack of insurance coverage are the most commonly cited causes of nonadherence. A belief that the medication would "cost too much" was cited by $55.5 \%$ of those failing to fill at least 1 prescription (2.4\% of respondents overall) while $20.2 \%$ cited "medicine not covered by insurance" as a reason for failing to fill. In the Craig et al. study, which assessed MCBS findings from 1996-1999, the percentages of communitydwelling elderly who reported failure to fill because they "thought it would cost too much" ranged from $0.6 \%$ in 1997 to $1.1 \%$ in 1999. Thus, our findings coupled with those of Craig et al. suggest that a growing proportion of Medicare enrollees were vulnerable to cost-related nonadherence prior to the implementation of Medicare Part D. ${ }^{9}$ A previous literature review found that up to $32 \%$ of older adults take less medication than prescribed because of costs. ${ }^{24}$

It is important to note that this survey was administered before the introduction of Medicare Part D, the new prescription 


\section{TABLE 2 Rates of Failure to Fill or Refill at Least One Prescription in 2004 by Medicare Sample Subgroup}

Population Attributes of Medicare Beneficiaries

\begin{tabular}{|c|c|c|c|c|c|c|}
\hline & Population & Population & Population & Population & & \\
\hline Total & $1,620,200$ & 4.4 & $35,294,380$ & 95.6 & & \\
\hline Age, years & & & & & 97.8 & $<0.001$ \\
\hline 18-64 (SSDI beneficiaries) & 568,740 & 10.4 & $4,912,380$ & 89.6 & & \\
\hline 65 years or older (retirement beneficiaries) & $1,051,460$ & 3.3 & $30,382,000$ & 96.7 & & \\
\hline Sex & & & & & 12.0 & 0.001 \\
\hline Male & 589,370 & 3.6 & $15,715,790$ & 96.4 & & \\
\hline Female & $1,030,830$ & 5.0 & $19,578,580$ & 95.0 & & \\
\hline Race & & & & & 6.8 & 0.010 \\
\hline White & $1,313,060$ & 4.2 & $30,128,930$ & 95.8 & & \\
\hline Nonwhite & 293,080 & 5.5 & $5,083,780$ & 94.5 & & \\
\hline Ethnicity & & & & & 3.1 & 0.080 \\
\hline Hispanic & 163,790 & 5.7 & $2,716,150$ & 94.3 & & \\
\hline Non-Hispanic & $1,455,120$ & 4.3 & $32,524,510$ & 95.7 & & \\
\hline Annual household income & & & & & 11.5 & $<0.001$ \\
\hline$<\$ 10,000$ & 334,990 & 4.9 & $6,532,710$ & 95.1 & & \\
\hline$\$ 10,001-\$ 20,000$ & 476,110 & 5.0 & $9,041,190$ & 95.0 & & \\
\hline$\$ 20,001-\$ 30,000$ & 345,070 & 5.0 & $6,527,550$ & 95.0 & & \\
\hline$>\$ 30,000$ & 388,060 & 3.2 & $11,555,170$ & 96.8 & & \\
\hline \multicolumn{7}{|l|}{ Supplemental insurance } \\
\hline Medicaid (dual eligibles) & 375,790 & 6.3 & $5,636,730$ & 93.7 & 15.1 & 0.001 \\
\hline Private supplemental (self-pay and employer paid) & 740,360 & 3.4 & $21,159,410$ & 96.6 & 31.4 & $<0.001$ \\
\hline Medicare HMO (Medicare Part C) & 246,690 & 4.1 & $5,835,480$ & 95.9 & 0.5 & 0.500 \\
\hline \multicolumn{7}{|l|}{$\begin{array}{l}\text { Chronic conditions (self-reported lifetime } \\
\text { history) }^{a}\end{array}$} \\
\hline Hypertension & $1,017,820$ & 4.5 & $21,386,670$ & 95.5 & 0.8 & 0.364 \\
\hline Arthritis & $1,137,130$ & 5.2 & $20,644,400$ & 94.8 & 26.3 & $<0.001$ \\
\hline Cardiovascular disease & 805,360 & 5.2 & $14,654,910$ & 94.8 & 9.0 & 0.003 \\
\hline Cancer & 489,340 & 4.3 & $10,879,000$ & 95.7 & 0.1 & 0.785 \\
\hline Diabetes & 427,470 & 5.5 & $7,341,830$ & 94.5 & 4.3 & 0.038 \\
\hline Psychiatric conditions & 556,720 & 8.0 & $6,445,410$ & 92.0 & 37.4 & $<0.001$ \\
\hline Emphysema, asthma, or COPD & 382,060 & 6.6 & $5,397,720$ & 93.4 & 20.0 & $<0.001$ \\
\hline Stroke or brain hemorrhage & 194,480 & 4.6 & $4,002,710$ & 95.4 & 0.1 & 0.717 \\
\hline Neurological disease & 145,730 & 5.0 & $2,783,360$ & 95.0 & 0.9 & 0.357 \\
\hline Number of self-reported chronic conditions ${ }^{a}$ & & & & & 7.3 & $<0.001$ \\
\hline None & 64,000 & 2.5 & $2,546,420$ & 97.5 & & \\
\hline 1 & 209,900 & 3.2 & $6,258,280$ & 96.8 & & \\
\hline 2 & 350,900 & 4.0 & $8,348,510$ & 96.0 & & \\
\hline 3 & 372,200 & 4.3 & $8,263,360$ & 95.7 & & \\
\hline 4 or more & 623,100 & 5.9 & $9,877,810$ & 94.1 & & \\
\hline
\end{tabular}

Source: 2004 Medicare Current Beneficiary Survey, Access to Care File, community resident sample

aself-reported conditions were identified by asking respondents, "Has a doctor ever told you that you had..." and then naming the condition.

$C O P D=$ chronic obstructive pulmonary disease $; H M O=$ health maintenance organization; SSDI = Social Security Disability Insurance; $X^{2}=$ chi-square
Filled All Prescriptions or

Had No Prescriptions

d to Fill 1 or More Prescriptions 


\section{TABLE 3 Classes and Subclasses of Prescriptions ${ }^{a}$ Not Filled/Refilled by Medicare Beneficiaries}

\begin{tabular}{|c|c|c|c|c|c|c|c|c|c|}
\hline $\begin{array}{l}\text { Drug } \\
\text { Class }\end{array}$ & $\begin{array}{l}\text { Drug } \\
\text { Subclass }\end{array}$ & $\begin{array}{l}\text { Sample } \\
\text { Rxs }\end{array}$ & $\begin{array}{l}\% \text { of } \\
\text { Class }\end{array}$ & $\begin{array}{c}\% \text { of } \\
\text { Total Rxs }\end{array}$ & $\begin{array}{l}\text { Drug } \\
\text { Class }\end{array}$ & $\begin{array}{c}\text { Drug } \\
\text { Subclass }\end{array}$ & $\begin{array}{l}\text { Sample } \\
\text { Rxs }\end{array}$ & $\begin{array}{l}\% \text { of } \\
\text { Class }\end{array}$ & $\begin{array}{c}\% \text { of } \\
\text { Total Rxs }\end{array}$ \\
\hline Total & & 993 & NA & 100.0 & \multicolumn{5}{|c|}{ Systemic anti-infectives } \\
\hline \multicolumn{5}{|c|}{ Central nervous system agents } & & Antibiotics & 46 & 92.0 & 4.6 \\
\hline & Nonsteroidal & 69 & 29.5 & 6.9 & & Other & 4 & 8.0 & 0.4 \\
\hline & anti-inflammatory drugs & & & & & & 50 & 100.0 & 5.0 \\
\hline & Antidepressant drugs & 54 & 23.1 & 5.4 & \multicolumn{5}{|c|}{ Gastrointestinal agents } \\
\hline & Narcotic analgesics & 36 & 15.4 & 3.6 & & \multirow{3}{*}{$\begin{array}{l}\text { Antacids/proton pump } \\
\text { inhibitors/H2 receptor } \\
\text { antagonists }\end{array}$} & \multirow[t]{3}{*}{40} & \multirow[t]{3}{*}{87.0} & \multirow[t]{3}{*}{4.0} \\
\hline & Anticonvulsants & 15 & 6.4 & 1.5 & & & & & \\
\hline & Anxiolytics/hypnotics & 13 & 5.6 & 1.3 & & & & & \\
\hline & \multirow{2}{*}{$\begin{array}{l}\text { Antipsychotics/antimanic } \\
\text { agents }\end{array}$} & \multirow[t]{2}{*}{12} & \multirow[t]{2}{*}{5.1} & \multirow[t]{2}{*}{1.2} & & Other & 6 & 13.0 & 0.6 \\
\hline & & & & & & & 46 & 100.0 & 4.6 \\
\hline & Skeletal muscle relaxants & 12 & 5.1 & 1.2 & \multicolumn{5}{|c|}{ Renal/Genitourinary agents } \\
\hline & Other & 23 & 9.8 & 2.3 & & Bladder agents & 11 & 68.8 & 1.1 \\
\hline & & 234 & 100.0 & 23.6 & & Other & 5 & 31.3 & 0.5 \\
\hline \multicolumn{5}{|c|}{ Cardiovascular agents } & & & 16 & 100.0 & 1.6 \\
\hline & Antihyperlipidemic agents & 80 & 44.0 & 8.1 & \multicolumn{5}{|c|}{ Miscellaneous } \\
\hline & \multirow{2}{*}{$\begin{array}{l}\text { Renin-angiotensin } \\
\text { antagonists }\end{array}$} & \multirow[t]{2}{*}{31} & \multirow[t]{2}{*}{17.0} & \multirow[t]{2}{*}{3.1} & & Hematologic agents & 10 & 22.2 & 1.0 \\
\hline & & & & & & Dermatologic agents & 8 & 17.8 & 0.8 \\
\hline & Antiadrenergics & 20 & 11.0 & 2.0 & & \multirow{2}{*}{$\begin{array}{l}\text { Nutrients/nutritional } \\
\text { agents }\end{array}$} & \multirow[t]{2}{*}{7} & \multirow[t]{2}{*}{15.6} & \multirow[t]{2}{*}{0.7} \\
\hline & Calcium channel blockers & 11 & 6.0 & 1.1 & & & & & \\
\hline & Other & 40 & 22.0 & 4.0 & & \multirow{2}{*}{$\begin{array}{l}\text { Benign prostatic } \\
\text { hypertrophy }\end{array}$} & \multirow[t]{2}{*}{5} & \multirow[t]{2}{*}{11.1} & \multirow[t]{2}{*}{0.5} \\
\hline & & 182 & 100.0 & 18.3 & & & & & \\
\hline \multicolumn{5}{|c|}{ Endocrine/Metabolic agents } & & Ophthalmic/otic agents & 5 & 11.1 & 0.5 \\
\hline & Bisphosphonates & 26 & 40.0 & 2.6 & & Immunologic agents & 5 & 11.1 & 0.5 \\
\hline & Oral hypoglycemiants & 12 & 18.5 & 1.2 & & Antineoplastic agents & 2 & 4.4 & 0.2 \\
\hline & Other & 27 & 41.5 & 2.7 & & Antimetabolites & 1 & 2.2 & 0.1 \\
\hline & & 65 & 100.0 & 6.5 & & Drugs for intermittent & 1 & 2.2 & 0.1 \\
\hline Respir: & atory agents & & & & & Craudication & & & \\
\hline & Bronchodilators & 30 & 51.7 & 3.0 & & Antimalarials & 1 & 2.2 & 0.1 \\
\hline & Antihistamines & 24 & 41.4 & 2.4 & & & 45 & 100.0 & 4.5 \\
\hline & Other & 4 & 6.9 & 0.4 & Untran & slatable $^{b}$ & 297 & & 29.9 \\
\hline & & 58 & 100.0 & 5.8 & & & & & \\
\hline
\end{tabular}

Source: 2004 Medicare Current Beneficiary Survey, Access to Care File, community resident sample.

a Unweighted counts and proportions are based on prescriptions, not respondents.

${ }^{b}$ Response lacked an identifiable drug name (see Methods section for details).

$\mathrm{H} 2=$ histamine $-2 ; \mathrm{NA}=$ not applicable; $\mathrm{R} x=$ prescription .

drug benefit implemented in 2006. Although Craig et al. found no relationship between failure to fill and prescription drug coverage,$^{14}$ rates of nonadherence may decline in future Medicare analyses if the program works as intended. There is some preliminary evidence of a modest decline in cost-related nonadherence in the program..$^{22}$

\section{Limitations}

The foremost limitation of this research is the inability to tie selfreported incidence to actual failure to fill prescriptions since we did not have access to an electronic database of pharmacy claims to verify respondents' reports. Second, these data are now 4 years old, and the self-reported failure to fill prescriptions preceded the implementation of Medicare Part D in January 2006. However, these data from 2004 will provide a baseline for comparison to beneficiary survey results in 2006 and thereafter. Third, this analysis uses a narrow operational definition of nonadherenceself-reported failure to fill a prescription. Patients may also reduce the dosage or frequency of medication use or reduce spending in other critical areas like food or housing. ${ }^{20}$ Fourth, the sample size for unfilled prescriptions is relatively small so comparative analyses of nonadherent patient attributes by drug 
class (e.g., identifying differences between those who fail to fill antidepressant or antipsychotic prescriptions) were not possible.

Finally, the dependent variables in the study are all selfreported, and patient recall bias is a potential threat to validity. ${ }^{48,49}$ The high rate (30\%) of ambiguous drug responses in the MCBS in 2004 highlights this limitation. A review of patient self-reports of prescription use has determined that patient recall declines over time, the salience of the treatment episode affects patient reports, the perceived social acceptability of the condition being treated (and other confounding issues) can affect recall, and patients don't report medication use with the same accuracy as other health care events (i.e., hospitalization). ${ }^{50}$

\section{Conclusions}

Medication nonadherence is an important and persistent problem for American seniors. The Medicare Part D prescription drug benefit was predicated, in part, on improving patient access and patient adherence by using managed care principles to reduce drug costs. This study provides a snapshot of the rate of failure to fill prescriptions in the period preceding implementation of the Medicare Part D drug benefit. These data might be used as a baseline to measure the effects of the Medicare Part D program related to nonadherence.

\section{Authors}

JAE KENNEDY, PhD, is an Associate Professor in the Department of Health Policy and Administration at Washington State University; IULIA TULEU, MD, MHPA, is an Internal Medicine Resident at Beaumont Hospital in Royal Oak, Michigan; and KATHERINE MACKAY, MHPA, is a medical student at the University of Washington.

AUTHOR CORRESPONDENCE: Jae Kennedy, PhD, Associate Professor, Department of Health Policy and Administration, College of Pharmacy, Washington State University, P.O. Box 1495, Spokane, WA 99210-1495; Tel.: 509.368.6971; Fax: 509.358.7984;

E-mail: jjkennedy@wsu.edu

\section{DISCLOSURES}

This study was funded by the U.S. Department of Education's National Institute on Disability and Rehabilitation Research, Field Initiated Research Grant H133G070055. However, the analysis and the interpretation of these findings do not necessarily represent the policy of the Department of Education and are not endorsed by the federal government.

All authors contributed approximately equally to the study concept and design. Tuleu performed the majority of the data collection, with assistance from Kennedy. Kennedy interpreted the data, with assistance from Tuleu and Mackay. Kennedy and Mackay wrote the majority of the manuscript, with assistance from Tuleu. Kennedy made the majority of the changes in revision of the manuscript.

\section{REFERENCES}

1. World Health Organization. Adherence to Long-Term Therapies. Evidence for Action. Geneva: WHO; 2003.
2. Sherman FT. Medication nonadherence: a national epidemic among America's seniors. Geriatrics. 2007;62(4):5-6.

3. Osterberg L, Blaschke T. Adherence to medication. N Engl J Med. 2005;353(5):487-97.

4. Moxey ED, O'Connor JP, Novielli KD, Teutsch S, Nash DB. Prescription drug use in the elderly: a descriptive analysis. Health Care Financ Rev. 2003; 24(4):127-41.

5. Cubanski J, Voris M, Kitchman M, Neuman T, Potetz L. Medicare Chartbook. Menlo Park: Kaiser Family Foundation; 2005.

6. Masoudi FA, Baillie CA, Wang Y, et al. The complexity and cost of drug regimens of older patients hospitalized with heart failure in the United States, 1998-2001. Arch Intern Med. 2005;165(18):2069-76.

7. Hauptman PJ, Pressler SJ, Sackner-Bernstein J, Ordronneau P, Udelson JE. Rationale and design of CASPER: compliance and quality of life study comparing once-daily carvedilol CR and twice-daily carvedilol IR in patients with heart failure. Am J Cardiol. 2006;98(7A):60L-66L

8. Chess D, Krentzman M, Charde J. Creating a wellness program/safety net for the medically complex and frail patient. J Ambul Care Manage. 2007; 30(1):30-38

9. Kennedy J, Coyne J, Sclar D. Drug affordability and prescription noncompliance in the United States: 1997-2002. Clin Ther. 2004;26(4):607-14.

10. Kirking DM, Lee JA, Ellis JJ, Briesacher B, McKercher PL. Patientreported underuse of prescription medications: a comparison of nine surveys. Med Care Res Rev. 2006;63(4):427-46.

11. Heisler M, Langa KM, Eby EL, Fendrick AM, Kabeto MU, Piette JD. The health effects of restricting prescription medication use because of cost. Med Care. 2004:42(7):626-34

12. Steinman MA, Sands LP, Covinsky KE. Self-restriction of medications due to cost in seniors without prescription coverage. J Gen Intern Med. 2001;16(12):793-99.

13. Mojtabai R, Olfson M. Medication costs, adherence, and health outcomes among Medicare beneficiaries. Health Aff. (Millwood). 2003;22(4):220-29.

14. Craig BM, Kreling DH, Mott DA. Do seniors get the medicines prescribed for them? Evidence from the 1996-1999 Medicare Current Beneficiary Survey. Health Aff. (Millwood). 2003;22(3):175-82.

15. Neuman P, Strollo MK, Guterman S, et al. Medicare prescription drug benefit progress report: findings from a 2006 national survey of seniors. Health Aff. (Millwood). 2007;26(5):w630-43.

16. Safran DG, Neuman P, Schoen C, et al. Prescription drug coverage and seniors: findings from a 2003 national survey. Health Aff. (Millwood). 2005; (suppl)Web exclusives: w155-wl66.

17. Klein D, Turvey C, Wallace R. Elders who delay medication because of cost: health insurance, demographic, health, and financial correlates. Gerontologist. 2004;44(6):779-87.

18. Kennedy J, Erb C. Prescription noncompliance due to cost among adults with disabilities in the United States. Am J Public Health. 2002;92(7):1120-24

19. Cunningham PJ. Affording Prescription Drugs: Not Just a Problem for the Elderly. Washington DC: Center for Studying Health System Change; 2002.

20. Soumerai SB, Pierre-Jacques M, Zhang F, et al. Cost-related medication nonadherence among elderly and disabled Medicare beneficiaries: a national survey 1 year before the Medicare drug benefit. Arch Intern Med. 2006; 166(17):1829-35.

21. Briesacher B, Limcangco R, Gaskin D. Racial and ethnic disparities in prescription coverage and medication use. Health Care Financ Rev. 2003; 25(2):63-76

22. Madden JM, Graves AJ, Zhang F, et al. Cost-related medication nonadherence and spending on basic needs following implementation of Medicare Part D. JAMA. 2008;299(16):1922-28. 
23. Bambauer KZ, Safran DG, Ross-Degnan D, et al. Depression and cost-related medication nonadherence in Medicare beneficiaries. Arch Gen Psychiatry. 2007;64(5):602-08

24. Briesacher BA, Gurwitz JH, Soumerai SB. Patients at-risk for cost-related medication nonadherence: a review of the literature. J Gen Intern Med. 2007;22(6):864-71.

25. Wilson IB, Schoen C, Neuman P, et al. Physician-patient communication about prescription medication nonadherence: a 50-state study of America's seniors. J Gen Intern Med. 2007;22(1):6-12.

26. Piette JD, Heisler M, Krein S, Kerr EA. The role of patient-physician trust in moderating medication nonadherence due to cost pressures. Arch Intern Med. 2005;165(15):1749-55.

27. Piette JD, Heisler M, Wagner TH. Cost-related medication underuse: do patients with chronic illnesses tell their doctors? Arch Intern Med. 2004;164(16):1749-55

28. Vik SA, Hogan DB, Patten SB, Johnson JA, Romonko-Slack L, Maxwell CJ. Medication nonadherence and subsequent risk of hospitalisation and mortality among older adults. Drugs Aging. 2006;23(4):345-56.

29. Shalansky SJ, Levy AR. Effect of number of medications on cardiovascular therapy adherence. Ann Pharmacother. 2002;36(10):1532-39.

30. Chesney M. Adherence to HAART regimens. AIDS Patient Care STDS. 2003;17(4):169-77.

31. Johnson FR, Ozdemir S, Manjunath R, Hauber AB, Burch SP, Thompson TR. Factors that affect adherence to bipolar disorder treatments: a statedpreference approach. Med Care. 2007;45(6):545-52

32. Sullivan PS, Campsmith ML, Nakamura GV, Begley EB, Schulden J, Nakashima AK. Patient and regimen characteristics associated with self-reported nonadherence to antiretroviral therapy. PLoS ONE. 2007; 2(6): 5552

33. Andersson K, Melander A, Svensson C, Lind O, Nilsson JL. Repeat prescriptions: refill adherence in relation to patient and prescriber characteristics, reimbursement level and type of medication. Eur J Public Health. 2005;15(6):621-26.

34. Piette JD, Heisler M, Horne R, Caleb Alexander G. A conceptually based approach to understanding chronically ill patients' responses to medication cost pressures. Soc Sci Med. 2006;62(4):846-57.

35. Elliott RA, Ross-Degnan D, Adams AS, Safran DG, Soumerai SB. Strategies for coping in a complex world: adherence behavior among older adults with chronic illness. J Gen Intern Med. 2007;22(6):805-10.

36. Gemmill MC, Thomson S, Mossialos E. What impact do prescription drug charges have on efficiency and equity? Evidence from high-income countries. Int J Equity Health. 2008;7(1):12.
37. Goldman DP, Joyce GF, Zheng Y. Prescription drug cost sharing associations with medication and medical utilization and spending and health. JAMA. 2007;298(1):61-69.

38. Fairman KA. The future of prescription drug cost-sharing: real progress or dropped opportunity? J Manag Care Pharm. 2008;14(1):70-82. Available at: www.amcp.org/data/jmcp/JMCPMaga_JanFeb\%2008_070-082.pdf.

39. Fairman KA, Motheral BR, Henderson RR. Retrospective, long-term follow-up study of the effect of a three-tier prescription drug copayment system on pharmaceutical and other medical utilization and costs. Clin Ther. 2003;25(12):3147-61; discussion 3144-46

40. Motheral B, Fairman KA. Effect of three-tier prescription copay on pharmaceutical and other medical utilization. Med Care. 2001; 39(12):1293-1304

41. Soumerai SB, McLaughlin TJ, Ross-Degnan D, Casteris CS, Bollini P. Effects of a limit on Medicaid drug-reimbursement benefits on the use of psychotropic agents and acute mental health services by patients with schizophrenia. N Engl J Med. 1994;331(10):650-55.

42. Soumerai SB, Avorn J, Ross-Degnan D, Gortmaker S. Payment restrictions for prescription drugs under Medicaid: Effects on therapy, cost and equity. N Engl J Med. 1987;317(9):550-56.

43. Taira DA, Iwane KA, Chung RS. Prescription drugs: elderly enrollee reports of financial access, receipt of free samples, and discussion of generic equivalents related to type of coverage. Am J Manag Care. 2003;9(4):305-12.

44. Heisler M, Wagner TH, Piette JD. Clinician identification of chronically ill patients who have problems paying for prescription medications. Am J Med. 2004;116(11):753-58

45. Centers for Medicare \& Medicaid Services. 2004 MCBS Access to Care Survey Codebook. Availabke at: www.cms.hhs.gov/MCBS/Downloads/ A04\%20Ric\%203.pdf. Accessed July 20, 2008.

46. Shah B, Barnewell B, Bieler G. SUDAAN User's Manual. Research Triangle Park, NC: Research Triangle Institute; 1997.

47. Drug Facts and Comparisons Publishing Group. Drug Facts and Comparisons. St. Louis: Wolters Kluwer Health; 2007.

48. Poisal JA. Reporting of drug expenditures in the MCBS. Health Care Financ Rev. 2003;25(2):23-36.

49. Urquhart J. Role of patient compliance in clinical pharmacokinetics. A review of recent research. Clin Pharmacokinet. 1994;27(3):202-15.

50. Evans C, Crawford B. Patient self-reports in pharmacoeconomic studies: their use and impact on study validity. Pharmacoeconomics. 1999; 15(3):241-56.

\section{Editor's Note}

The year 2020 marks the 25th anniversary of the Journal of Managed Care E Specialty Pharmacy. To commemorate this milestone, we are publishing a series of articles that document the changes to the journal and profession over the past 2 and a half decades. Each month we reprint an original article from a previous year, dating back to 1995. The reprinted articles feature topics of significance in our industry. Each reprinted article is accompanied by a contemporary reflection that will consider the historical significance of the topic, as well as the current and future state.

Laura E. Happe, PharmD, MPH Editor-in-Chief 